\title{
Interação dos atores no ambiente aprendiz: o caso da saúde*
}

\section{Solange Mostafa}

Professora doutora vice-coordenadora do mestrado em educação da Universiade do Vale do Itajaí (Univali).

E-mail:smostafa@terra.com.br

\section{Resumo}

Discorre sobre as interações, a aprendizagem e as bibliotecas na área da saúde, tendo como referencial teórico a filosofia da multiplicidade de Deleuze e Guattari. Apresenta um levantamento da literatura recente brasileira sobre usuários de informação em bibliotecas universitárias, sistematizando os objetivos, as metodologias e os resultados alcançados em cada estudo.

\section{Palavras-chave}

Interações. Bibliotecas. Filosofia da multiplicidade.

\section{Interaction of the actors in the learning environment: the case of health}

\section{Abstract \\ It discourses on the interactions, the learning and the libraries in the area of health, having as referencial theoretician the philosophy of the multiplicity of Deleuze \& Guattari; it presents a survey of Brazilian recent literature on users of information in university libraries, showing the objectives, the methodologies and the results reached in each study.}

\section{Keywords}

Interactions. Libraries. Philosophy of multiplicity.

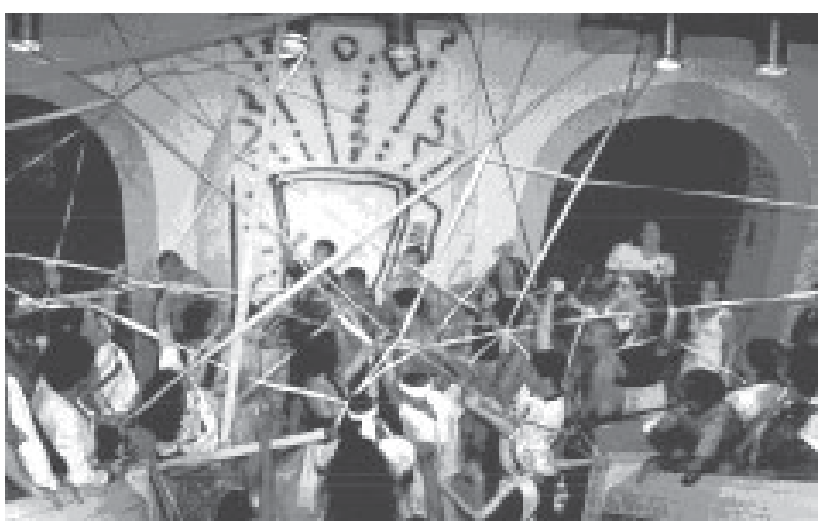

\section{INTRODUÇÃO}

Três possibilidades teóricas me ocorreram quando convidada para falar sobre interações, aprendizagem e bibliotecas na área da saúde. A rede de atores de Bruno Latour, as teorias clássicas da aprendizagem (Piaget e Vygtosky) e a filosofia do virtual em Deleuze e Guattari. Como tudo está circunscrito a espaço-tempos, o tema foi-me sugerido por ocasião da passagem de Ada Kroef por Itajaí, o que significou pensar o tema com a filosofia da diferença. Isso permitia incluir a rede de atores de Latour, mas significava também ter de desconsiderar as teorias clássicas da aprendizagem, deixando de lado a dialética indivíduo-sociedade desenvolvida pelo marxismo.

A foto ${ }^{* *}$ acima mostra um processo de transversalização de fluxos em um espaço; são experimentações possíveis a partir do conceito de rizoma dos filósofos franceses Gilles Deleuze e Félix Guattari. A foto mostra pessoas atravessadas por linhas de todo tipo; é uma maneira de entender o mundo por linhas; essa concepção do mundo por linhas dá a idéia de movimento, de velocidade, de mutação. "Acreditamos que as linhas são os elementos constitutivos das coisas e dos acontecimentos" (DELEUZE, 1992 p. 47).

\footnotetext{
* Baseado em palestra proferida no Congresso Brasileiro de Ensino Médico (Cobem), por meio da Rede de Apoio ao Ensino Médico (Raem), Natal, out. 2005.

** Essa foto é de Isabel Gouveia e refere-se à peça "A homepage de Matilde", pelo Grupo de Teatro do Liceu de Artes e Oficios da Bahia. Está disponibilizada na página de Nelson Pretto, que nos autorizou utilizá-la (www.pretto.info).
} 
Há linhas flexíveis, linhas duras, linhas que segmentarizam, estriam os espaços lisos; linhas que cortam, interceptam, alteram, desviam de determinado percurso, linhas de fuga que produzem espaços lisos. Linhas que atravessam diferentes planos; outras que ficam no mesmo plano. Enfim, as linhas se distribuem como um rizoma tal como foi descrito por Deleuze e Guattari. "Não existem pontos ou posições num rizoma como se encontra numa estrutura, numa árvore, numa raiz. Existem somente linhas" (DELEUZE; GUATTARI, 1995, p.17). Assim, "há tipos de linha muito diferentes, na arte, mas também numa sociedade, numa pessoa" (DELEUZE; GUATTARI, 1992, p. 47)

Pensar o mundo por linhas supõe abandonar a lógica dialética que nos acompanhou por mais de um século na tríade afirmação, negação e superação, pensando-o na sua imanência, onde se produz com e no mundo, na potência de vida e na afirmação da diferença; mas não se trata mais de uma diferença opositiva, mas uma diferença da diferença, portanto, sem referente, sem modelo; um processo de singularização não comparável nem mensurável. Singularizações produzidas por conexões, velocidades e diferentes intensidades que adquirem consistências. Encontros, cruzamentos de fluxos de diferentes naturezas e proveniências.

O que está em jogo nos teóricos "pós-modernos” não é mais a consciência humana e não é mais o aprendizado por meio da consciência ou da autoconsciência, mas é o aprendizado pelos fluxos, por agenciamentos, por maquinismos e por arranjamentos. E sobretudo um plano de imanência no qual se criam os conceitos de toda a filosofia. A separação sujeito-objeto, consciência e mundo, caverna platônica e mundo das idéias acabou introduzindo a transcendência e a interioridade; os filósofos da diferença lutam contra a representação do mundo pela consciência; instauram um plano de imanência no qual aquela separação não pode existir mais; os autores querem experimentar o mundo sem transcendências.

Que conseqüências traz pensar o mundo por imanências?

Todos os processos se produzem sobre o plano de imanência... quando se invoca uma transcendência, interrompe-se o movimento, para introduzir uma interpretação em vez de experimentar (DELEUZE, 1992, p. 182).

Ao traçarmos o plano de imanência (já que o plano precisa ser construído), a realidade já pode ser vivida como multiplicidade, produção de produção, autopoieses; tudo é imanente e os agenciamentos coletivos de enunciação e maquínicos do desejo conectam-se em um maquinismo cujo princípio é o da gagueira da conjunção e... e... e..., não mais o ou; o mundo como perpétua relação, que se refaz, se diferencia do que era permanentemente; mundo-mutante.

Trata-se, portanto, de uma filosofia da experimentação, da produção do novo, do fora. As mudanças produzemse nos movimentos de ruptura aos modelos, referentes e estereótipos. Conexões com o fora, traçando linhas de fuga; toda a criação, a invenção, produz desterritorializações, um embaralhamento dos códigos; o rizoma sugere uma imagem do pensamento, uma imagem-mundo constituída por linhas, mundo-linhas, que se espalha na horizontalidade, na superfície, por deslizamento, como o crescimento da grama. Um mapa cartografado pela marcação das linhas e seus movimentos. Em Mil Platôs, os filósofos apresentam o rizoma em contraposição à imagem arborescente do pensamento moderno ocidental. Rizoma que não é a raiz da árvore porque esta tem um caule central, com suas ramificações, mas como a raiz da grama ou da erva daninha, sem profundidade, mas crescendo por todos os lados, ocupando o entre, os espaços não cultivados.

Como se produz a singularidade, a criação? A invenção se dá quando as linhas de virtualidade são atualizadas. Todo o atual tem uma névoa de virtualidade, de partículas que existem como potência, como possibilidade, mas esta atualização nem sempre é criação, ruptura; ela pode se atualizar em um movimento de captura, de reterritorialização. $O$ rizoma é então uma imagem do pensamento que os filósofos Deleuze e Guattari inventam para explicar como poderíamos pensar por multiplicidade, pela produção da diferença, uma vez que os autores são intelectuais militantes das décadas de 70, investindo contra toda forma de opressão, seja a opressão das interpretações teóricas, seja a opressão vinda das relações sociais.

A proposta filosófica deles é a experimentação e invenção do novo, não a repetição do mesmo. Portanto, tudo que repete deve ser combatido em favor da afirmação da diferença, da singularidade. Por isso, são chamados filósofos da diferença e nomeiam a sua filosofia de filosofia da multiplicidade.

Desde já entendamos que

toda multiplicidade implica elementos atuais e virtuais. Não há objeto puramente atual. Todo atual rodeia-se de uma névoa de imagens virtuais (DELEUZE, 1996 p. 49). 
A questão do virtual ganha importância para os bibliotecários em função das bibliotecas virtuais. O ciberespaço limitou uma possível exploração entre o virtual/atual, pois limitamos um sentido para o virtual, o qual remetia ao ciberespaço e à Internet. Contudo, quando Deleuze e Guattari explicaram a sua filosofia do virtual, a Internet não existia.

Bibliotecários, restringimo-nos à rede de Pierre Levy que utiliza a filosofia da diferença para explicar as tecnologias da inteligência e, principalmente, para explicar o seu conceito de inteligencia coletiva. Como conseqüência, no território bibliotecário, fica a idéia de que virtual é algo do ciberespaço. Mas retomemos esta idéia fora do ciberespaço a fim de experimentarmos o conceito de rizoma em outros territórios.

\section{Bibliotecas, laboratórios e salas de aula}

Pode-se conceber as salas de aula, os laboratórios e as bibliotecas das universidades como espaços de transversalizações de multiplicidade de elementos virtuais e atuais. As multiplicidades, ao variarem suas dimensões, mudam também sua natureza e se transformam.

Uma multiplicidade não tem nem sujeito nem objeto, mas somente determinações, grandezas, dimensões que não podem crescer sem que mudem de natureza (DELEUZE; GUATTARI, 1995, p. 16).

Assim, a sala de aula como espaço transversal ou ambiente aprendiz é produzida por linhas de todo tipo. A sala de aula é multiplicidade, é um rizoma; dependendo de alguns tipos de linhas que se cruzam, a sala de aula transborda em biblioteca. "O rizoma ...não tem começo nem fim, mas sempre um meio pelo qual ele cresce e transborda" (Idem, 1995 p. 32).

A sala de aula torna-se biblioteca (devir), quando o professor, como intercessor qualitativo, dispara estratégias, interceptando fluxos, levantando problemas diante dos quais o aluno tem de ir à biblioteca fazer buscas e consultar os textos para se sintonizar com a literatura publicada no tema; é o caso do aprendizado baseado em problemas, conhecido na área médica por Problem Based Learning (PBL), estratégia pioneira na área de medicina, mas também utilizada em outras áreas do ensino superior.

É como se a sala de aula contivesse traços de virtualidade que se atualizam em biblioteca toda vez que os planos de ensino listam as obras a serem consultadas na biblioteca.
As multiplicidades se definem pelo fora: pela linha abstrata, linha de fuga ou de desterritorialização segundo a qual elas mudam de natureza ao se conectarem às outras (Idem, p. 17).

A biblioteca, por sua vez, é um espaço transversal, rizomático, que produz linhas velozes que se cruzam. Algumas, tão velozes, que arrastam a biblioteca, em um nomadismo. A biblioteca cresce e transborda, atualizando-se em sala de aula toda vez que vemos o movimento de estudantes e professores na interação com os textos, na interação entre si e na relação do bibliotecário-usuário ensinando as fontes. $\mathrm{O}$ bibliotecário tem sido chamado a ensinar a aprender-a-aprender as fontes como exigência desta desterritorialização dos territórios de aprendizagem.

O rizoma é sempre multiplicidade que não pode ser reduzido à unidade; os territórios de aprendizagem implicam-se uns nos outros, promovendo diferenciações.

Os laboratórios, como as bibliotecas, foram chamados por Bruno Latour de 'centro de cálculos'. Autor também inspirado na mesma filosofia da multiplicidade de Deleuze, Bruno Latour relata que a ciência em ação nos laboratórios é diferente da ciência que vemos publicada nas revistas científicas, porque há toda uma implicação do laboratório com o lado de fora, tornando-o uma multiplicidade de relações rizomáticas (o financiamento das pesquisas, a seleção das linhagens de cobaias no laboratório, a seleção das plantas medicinais, seres vivos que não encontramos na natureza, mas que são produzidos para o laboratório; mesmo os agentes químicos para as reações dos tubos de ensaio são substâncias produzidas com a pureza exigida nos experimentos; tudo isso deixa o laboratório muito longe da natureza lá fora, parecido mais com uma negociação, uma construção da verdade do que o mundo natural; relações construídas que ficam apagadas na publicação do relato da pesquisa na forma de artigo científico. $\mathrm{O}$ artigo de ciência que temos nas bases de dados é então não a representação do mundo dos fatos naturais, mas certa construção da verdade. Por isso, o artigo da ciência é problematizado como artefato cultural (MOSTAFA, 2004).

A noção de artefatos culturais tensiona um pouco a noção de fato natural. A ciência não lidaria apenas com fatos naturais porque esses fatos são permanentemente reconstruídos no laboratório; a ciência não seria mais vista como representação da realidade na forma de espelho do mundo, mas muito mais como uma construção interessada em um certo mundo. Representada então por um certo documento. $\mathrm{O}$ documento científico seria essa 
tecnologia literária para produzir certos efeitos de verdade. Nesse sentido, os estudos sociais ou culturais da ciência seriam surpreendidos por dois marcos teóricos importantes: um trazido pelo trabalho de Shapin e Shaffer, com os esforços de Boyle na nascente ciência do século 17 para construir uma tecnologia literária que facilitasse o testemunho virtual dos fatos científicos, e outro na 'Vida de Laboratório; a produção dos fatos científicos' de Bruno Latour em fins da década de 70 (LENOIR, 1997).

O laboratório é então um agenciamento, um arranjamento para produzir certos efeitos e certas verdades. ( $\mathrm{O}$ médico-propaganda de laboratório que a mídia tem noticiado é um exemplo do que o Bruno Latour está chamando de centro de cálculo): complexas relações do lado de fora do laboratório que fazem dele uma multiplicidade, um rizoma.

Em algumas áreas de ciência, podemos dizer que as bibliotecas não existiriam sem os laboratórios. Outra vez podemos dizer que a biblioteca é uma virtualidade que se atualiza em laboratório ao trazer evidências explicitadas nos registros das bases de dados. (Note-se que a base de dados Cochrane é uma base de evidências científicas na área da saúde, isto é, reúne artigos de revisão da literatura em saúde, reportando os achados científicos de forma suscinta e comparada para possibilitar a checagem dessas evidências publicadas no leito do enfermo ou na consulta médica em hospitais, clínicas ou postos de atendimento). "Medicina baseada em evidências" já é título de livro (SACKETT et al. 2003)

Frohmann entende, baseado em Knorr-Cetina, que o artigo não teria a função mediadora de veículo de informação, mas seria um recurso discursivo cuja principal finalidade consistiria em eliminar as contingências e as situacionalidades do laboratório. Para Knorr-Cetina, há processos de conversão entre o que se passa no laboratório e o que se passa nos artigos de ciência, como se fosse a conversão de uma moeda para outra, de um jogo de linguagem para outro. $\mathrm{O}$ apagamento das particularidades do laboratório é logo preenchido pelo paper em sua função discursiva-recursiva de objetivar a ciência e o mundo natural. Se a natureza é simulada no laboratório, este é outra vez simulado no artigo de ciência. Falamos então de uma dupla virtualidade: não só as testemunhas estão ausentes da cena, como a cena ela mesma é um constructo discursivo. Para Frohmann, como também para Knorr-Cetina, a continuidade das práticas não surge da coerência lógica dos espaços de informação, mas pelo trabalho de conversão entre os campos científicos e não científicos.
O laboratório atualizado rodeia-se de uma névoa de imagens virtuais que é a biblioteca para ele. Quando o antropólogo Latour observa o laboratório, ele se pergunta que relação há entre a parte A do laboratório, que são os escritórios e bibliotecas, e a parte B, onde estão as bancadas.

Os artigos são considerados pela equipe [do laboratório] como produto de sua usina singular... os artigos, longe de serem os relatórios do que foi produzido na fábrica .... [contém] diagramas que ...são exatamente os documentos produzidos na seção B, alguns dias ou algumas semanas atrás.

Assim, uma grande quantidade de literatura emana do laboratório. $\mathrm{O}$ empirismo radical de Bruno Latour atesta, então:

A mesa surge como o eixo central de nossa unidade de produção, uma vez que é sobre ela que se fabricam novos esboços de artigos, por justaposição dos dois tipos de literatura: a que vem do exterior e a produzida no laboratório (Idem, p. 40).

O autor constata dois tipos de literatura que precisam entrar em sintonia:

Os artigos de revista cobrem a mesa de um dos "doutores" da sessão A; distingue-se à esquerda um número aberto da Science, e, à direita um esquema que não passa de um resumo dos dados empilhados mais adiante, também à direita. É como se os dois tipos de literatura estivessem justapostos: publicações externas ao laboratório e documentos produzidos no interior do laboratório (LATOUR, 1997, p. 40).

Assim, a natureza é simulada no laboratório e, outra vez, no artigo científico, este também tendo ainda de encontrar uma continuidade possível com os textos já publicados pelo laboratório.

\section{Clínicas, creches, hospitais, postos de saúde: ambientes aprendizes}

Não podemos falar em ambientes aprendizes na área de saúde sem considerar as clínicas, os postos de saúde, as creches, os hospitais, os lugares de atendimento, o lado de fora das bibliotecas onde um novo padrão de acolhimento na atenção primária à saúde está sendo gestado, em espaços de produção da vida.

Nestes espaços de produção da vida, são gestados os saberes locais a serem considerados nos acervos da biblioteca universitária, saber que vem dos tccs, das monografias, das dissertações e teses de mestrado e 
doutorado, trazendo os dados e a resolução dos problemas de saúde da comunidade. O saber local, como diz Foucault,

não é de forma alguma um saber comum, um bom senso, ao contrário, um saber particular, regional, local, um saber diferencial, incapaz de unanimidade e que só deve sua força à dimensão que opõe a todos aqueles que os circundam (FOUCAULT, 1979, p. 170).

Todo esse lado de fora atravessa a biblioteca, tornando-a diferente, tornando-a mais potente, com mais possibilidades. Esse é o grande rizoma da saúde em que o bibliotecário está implicado.

Não se trata de integração de saberes. Importa fazer rizoma. Viabilizar conexões e conexões; conexões sempre novas. Fazer rizoma com os alunos, rizomas entre os alunos (GALLO, 2003 p.82);

fazer rizomas com os professores e busca de diferenciação no atendimento ao usuário de bibliotecas.

Quais são os seis princípios básicos do rizoma? Princípio de conexão: qualquer ponto do rizoma pode ser conectado a qualquer outro. Princípio de heterogeneidade, que é quase uma conseqüência da conectividade; se qualquer ponto pode ser conectado com qualquer outro, é de se esperar que os pontos conectados sejam de natureza diferente. O princípio da multiplicidade sugere que o rizoma não é nem sujeito nem objeto, mas multiplicidade; o princípio da ruptura assignificante vai dizer que o rizoma prescinde de processos de significação, causando dificuldades para as teorias de aprendizagem tradicionais (DELEUZE; GUATTARI, 1995, p.15-37). Os dois últimos princípios (multiplicidade e ruptura assignificante) colocam grandes diferenças teóricas à teoria da aprendizagem.

A aprendizagem mais clássica ligada ao nome de Piaget ou Vygotsky lida com um sujeito psicológico conhecedor, significador, que significa o mundo com a linguagem; é esse sujeito que os filósofos da multiplicidade e da diferença não aceitam mais. Romperam com essas noções de sujeito e de objeto, por elas levarem à transcendência. Não há sujeitos mais nos rizomas. Há apenas agenciamentos coletivos de enunciação e maquínicos do desejo. $\bigcirc$ rizoma não pressupõe nenhum processo de significação e a produção de sentido é o cerne da teorização de Vygotsky: o homem, através da linguagem, significa o mundo. Portanto, o outro me traz o mundo já significado, daí a importância do outro e das relações humanas na obra de Vygotsky, com um conceito importante que é a zona de desenvolvimento proximal para valorizar as interações na aprendizagem. Mas quem pensa por rizomas vai duvidar da concepção de linguagem e de cultura do Vygtosky, pelo seu antropocentrismo, ambas as categorias excessivamente antropológicas. Os filósofos da diferença vão entender a linguagem como agenciamento, como arranjamento, porque a linguagem não apenas signfica o mundo, mas a linguagem está atravessada por relações de saber-poder. Então falar não é só uma questão de dar sentido ao mundo, mas é também uma questão de direcionar fluxos, fazer acontecer algumas coisas e interromper outras. A separação entre os instrumentos técnicos e os instrumentos simbólicos, típico no pensamento Vygtoskiano, também não encaixa bem com o conceito de inteligência coletiva oriunda da filosofia da multiplicidade, na qual a técnica seria considerada um elemento não humano a agenciar as intencionalidades humanas.

Outro princípio do rizoma é a cartografia. E aqui quero voltar aos estudos de usuários de biblioteca; os estudos que localizei realizados por bibliotecários da área de saúde. Eles, de alguma maneira, lembram o paradigma arborescente, e não o rizomático. $\bigcirc$ princípio da cartografia sugere que o mapa da biblioteca seja traçado como uma superfície de vários caminhos, em amplas regiões de várias altitudes e latitudes; é diferente do organograma da biblioteca, que tem uma estrutura fechada que remete sempre aos mesmos pontos centrais. Mapear é descobrir novos lugares, regiões inusitadas que vão aparecendo à medida que vamos explorando o território, traçando seus movimentos de desterritorialização e reterritorialização.

É aqui que podemos experimentar mais, na descoberta de novas possibilidades de transversalizações com os usuários produzindo rizoma. Os estudos tradicionais de usuário de biblioteca trazem uma compreensão do usuário como alguém que preenche formulários, e não na sua multiplicidade, como um agenciamento coletivo de enunciação e maquínico do desejo.

O problema não é novo e, desde a década de 70, os estudos insistem na fase do diagnóstico. O diagnóstico é importante, mas, se olharmos bem para a tabela 1 (a seguir), vamos ver que algo se repete: Seria a metodologia? Seria a lógica da pesquisa? Seria a concepção do usuário como alguém que preenche formulários e responde a questões? Como é que podemos compor novos agenciamentos nos espaços de transversalizações?

Se estamos diante de uma proposta de invenção, como poderemos traçar linhas de fuga, linhas de corte nesses 
estudos da tabela 1, interceptando-os em fluxos-cortes que nos levem a novos territórios metodológicos e existenciais?

$\mathrm{Na}$ literatura internacional há alguns avanços em relação aos diagnósticos realizados de forma mais comparativa em episódios de acompanhamento do aluno de medicina, entendendo as diferentes necessidades de informação ao longo do curso até a residência (SHERHNEVA et al.2005). Os estudos usam expressões como 'história natural' do aprendizado sobre as fontes para mostrar que o usuário tem uma história com as fontes. No primeiro ano da faculdade, é um tipo de percepção das fontes. No terceiro ano, é outro. Na residência média, é outro. Então, não tem sentido entender o usuário em apenas um ponto da sua vida com as fontes.

Não é que esbocem uma cartografia, mas utilizam entrevistas que já é uma maneira mais próxima do que o simples formulário rápido e impessoal das bibliotecas, como em Thompson (1997). Outros armam estratégias referidas a episódios de aprendizagem que, embora cognitivistas, são estudos que contemplam fases e estágios variados dentro da formação, dando alguma idéia de movimento, como em Slotnnick, Harris e Antonenko (2001).

Nota-se que as pesquisas americanas mencionadas não são realizadas por bibliotecários, mas por médicos e outros profissionais. Na educação brasileira, há uma discussão há dez anos sobre o professor reflexivo e o professor pesquisador, aquele capaz de refletir sobre a prática sem sair dela (PIMENTA; GHEDIN, 2002); uma discussão para acontecer também na área de informação, que inclua a formação continuada de bibliotecários. Formação continuada é um dos temas mais discutidos em educação, dada a ampla rede de professores no país.
TABELA 1

Relatos tradicionais de bibliotecas na área da saúde

\begin{tabular}{|c|c|c|c|c|}
\hline & Objetivos & $\begin{array}{l}\text { População } \\
\text { estudada }\end{array}$ & Metodologia & Resultados /comentários \\
\hline $\begin{array}{l}\text { Costa } \\
\text { Lima, H.M } \\
2004\end{array}$ & $\begin{array}{l}\text { Identificar } \\
\text { experiências e } \\
\text { necessidades de } \\
\text { médicos residentes } \\
\text { da Famema quanto } \\
\text { ao uso de fontes e } \\
\text { bibliotecas durante a } \\
\text { graduação, } \\
\text { destacando os } \\
\text { residentes formados } \\
\text { na abordagem do } \\
\text { PBL (Problem Based } \\
\text { Learning) }\end{array}$ & $\begin{array}{l}105 \text { médicos } \\
\text { residentes } \\
\text { distribuídos } \\
\text { entre } 1^{\circ} \text { ano } \\
\text { ( } 50 \text { vagas, } \\
\text { sendo } 10 \text { no } \\
\text { PSF); } 2^{\circ} \text { ano } \\
\text { ( } 33 \text { vagas); } 3^{\circ} \\
\text { ano (14 } \\
\text { vagas) e } 4^{\underline{o}} \\
\text { ano (8 vagas) }\end{array}$ & Questionário & $\begin{array}{l}\text { Quase a metade }(44,5 \%) \\
\text { dos residentes está saindo } \\
\text { da graduação sem } \\
\text { capacitação em buscas de } \\
\text { informação; os formados } \\
\text { na abordagem PBL } \\
\text { conhecem melhor os } \\
\text { recursos informacionais. }\end{array}$ \\
\hline $\begin{array}{l}\text { Girello M. } \\
2002\end{array}$ & $\begin{array}{l}\text { Levantar motivos do } \\
\text { desinteresse dos } \\
\text { usuários com relação } \\
\text { ao serviço de } \\
\text { treinamento e } \\
\text { consulta às Bases de } \\
\text { Dados da Fac. } \\
\text { Odontologia de } \\
\text { Piracicaba da } \\
\text { Unicamp; conhecer } \\
\text { fatores dificultadores } \\
\text { existentes }\end{array}$ & $\begin{array}{l}79 \text { usuários } \\
\text { distribuídos } \\
\text { entre alunos } \\
\text { de graduação } \\
\text { e pós, } \\
\text { especialização } \\
\text { e professores }\end{array}$ & $\begin{array}{l}\text { Questionário } \\
\text { (anexado) }\end{array}$ & $\begin{array}{l}\text { O desinteresse era devido à } \\
\text { autonomia de metade dos } \\
\text { usuários que já sabiam usar } \\
(52,1 \%) \text {, a totalidade dos } \\
\text { usuários confirmam a } \\
\text { necessidade do serviço. }\end{array}$ \\
\hline $\begin{array}{l}\text { Peixoto, } \\
\text { M.A.P; } \\
\text { Mattos, } \\
\text { T.M. } \\
2000\end{array}$ & $\begin{array}{l}\text { Identificar principais } \\
\text { títulos de livros em } \\
\text { algumas faculdades } \\
\text { de medicina nos } \\
\text { estados do RJ, SP e } \\
\text { MG e critérios de } \\
\text { aquisição do livro e } \\
\text { de outros recursos } \\
\text { instrucionais pelos } \\
\text { estudantes. }\end{array}$ & $\begin{array}{l}956 \text { alunos de } \\
\text { graduação de } \\
\text { medicina e } \\
\text { enfermagem } \\
\text { em oito IES } \\
\text { de três estados }\end{array}$ & Questionário & $\begin{array}{l}\text { Dsciplinas cobertas pelos } \\
\text { livros mais comprados são: } \\
\text { Medicina Preventiva, } \\
\text { Ginecologia e Bioquímica. } \\
\text { O livreiro da escola é o } \\
\text { maior local de compra, } \\
\text { funcionando como agente } \\
\text { integrador entre alunos e } \\
\text { professores. O critério para } \\
\text { compra é a indicação dos } \\
\text { professores, e a finalidade } \\
\text { da compra são as provas } \\
\text { curriculares. Livro-texto, } \\
\text { nota de aula e apostila são } \\
\text { os recursos mais utilizados, } \\
\text { nesta ordem. } \\
\end{array}$ \\
\hline $\begin{array}{l}\text { Cuenca, } \\
\text { A..M. } 1999\end{array}$ & $\begin{array}{l}\text { Avaliar capacitação } \\
\text { de curso avançado } \\
\text { de acesso às Bases de } \\
\text { Dados e qual o nível } \\
\text { de autonomia } \\
\text { alcançado no uso } \\
\text { das bases. }\end{array}$ & $\begin{array}{l}92 \text { alunos de } \\
\text { pós-graduação } \\
\text { e docentes da } \\
\text { FSP/USP os } \\
\text { quais } \\
\text { receberam } \\
\text { capacitação } \\
\text { entre } 1993 \text { e } \\
1995 \text { ( } 29 \\
\text { capacitações) }\end{array}$ & $\begin{array}{l}\text { Questionário } \\
\text { (anexado) }\end{array}$ & $\begin{array}{l}65,2 \% \text { conseguiram } \\
\text { autonomia; } 15,25 \\
\text { solicitaram buscas } \\
\text { mediadas pelo } \\
\text { bibliotecário; } 19,6 \% \text { não } \\
\text { realizaram busca na } \\
\text { biblioteca }\end{array}$ \\
\hline $\begin{array}{l}\text { Curty, } \\
\text { M.G. } \\
1999\end{array}$ & $\begin{array}{l}\text { Identificar motivos } \\
\text { dos médicos } \\
\text { docentes na busca e } \\
\text { obtenção de } \\
\text { disseminação da } \\
\text { informação } \\
\text { produzida por eles e } \\
\text { dificuldades } \\
\text { encontradas no } \\
\text { acesso e obtenção da } \\
\text { informação em sua } \\
\text { área. }\end{array}$ & $\begin{array}{l}72 \text { docentes } \\
\text { médicos da } \\
\text { UEM (PR) }\end{array}$ & $\begin{array}{l}\text { Questionário } \\
\text { e Entrevistas }\end{array}$ & $\begin{array}{l}\text { O desenvolvimento da } \\
\text { carreira acadêmica é o } \\
\text { primeiro maior motivo de } \\
\text { busca }(51,4 \%) \text {. No } \\
\text { processo de ensino dá-se a } \\
\text { forma privilegiada de } \\
\text { disseminação da } \\
\text { informação ( } 88,9 \%) \text {. } \\
\text { Material desatualizado e } \\
\text { falta de tempo são as } \\
\text { maiores dificuldades } \\
\text { encontradas. Livros-texto } \\
\text { (73,6\%) e revistas } \\
\text { científicas ( } 51,4 \%) \text { são as } \\
\text { fontes de informação mais } \\
\text { utilizadas pelos médico- } \\
\text { docentes. }\end{array}$ \\
\hline
\end{tabular}


Notamos que as pesquisas bibliotecárias seguem o mesmo estilo, mesmo quando são realizadas em biblioteca centrais que não sejam especializados em saúde, como na tabela 2 .

Ações informacionais fora da biblioteca são linhas de fuga necessárias como na tabela 3, mas os estudos ainda não são cartografias, limitando-se a mapeamentos ou a descrições de serviços.

Um pouco mais de esforço teórico viabilizaria a produção de cartografias bibliotecárias, trazendo para a literatura profissional de bibliotecários relatos de processos rizomáticos em espaços de transversalização de saberes, nos quais possamos traçar os movimentos de desterritorialização e reterritorialização dos processos de produção de saberes. Como na foto inicial de uma experimentação rizomática, na qual não há centro no processo de aprendizagem e todos aprendem com todos.
TABELA 2

Relatos de ações informacionais fora de bibliotecas de saúde

\begin{tabular}{|c|c|c|c|c|}
\hline & Objetivos & $\begin{array}{l}\text { População } \\
\text { estudada }\end{array}$ & Metodologia & $\begin{array}{l}\text { Resultados/ } \\
\text { comentários }\end{array}$ \\
\hline $\begin{array}{l}\text { Marquetis, E. } \\
\text { M. et al. } \\
2003\end{array}$ & $\begin{array}{l}\text { Avaliar capacitação } \\
\text { usuários da Unicamp } \\
\text { do } 1^{\circ} \text { semestre } 2002 \\
\text { em quatro módulos } \\
\text { instrucionais }\end{array}$ & $\begin{array}{l}\text { Não informa o } \\
\text { número de } \\
\text { avaliados }\end{array}$ & $\begin{array}{l}\text { Escala de } \\
\text { quatro notas } \\
\text { (ruim a ótimo) } \\
\text { em oito itens } \\
\text { - anexo }\end{array}$ & $\begin{array}{l}\text { Módulo I: Bom; } \\
\text { Módulo II:Bom e } \\
\text { ótimo; Módulo III: } \\
\text { ótimo e bom; } \\
\text { Módulo IV:Bom }\end{array}$ \\
\hline $\begin{array}{l}\text { Moser, E.; } \\
\text { Accetta, I. R. } \\
2003\end{array}$ & $\begin{array}{l}\text { Relato de experiência } \\
\text { sobre a rotina de } \\
\text { treinamento da } \\
\text { Biblioteca Central da } \\
\text { Furb (SC); descreve a } \\
\text { experiência sem } \\
\text { dados }\end{array}$ & $\begin{array}{l}\text { Não informa o } \\
\text { número de } \\
\text { avaliados: } \\
\text { Grupo 1 } \\
\text { (calouros), } 2 \text { hs } \\
\text { de } \\
\text { treinamento; } \\
\text { Gp } 2 \text { (Tcc): } \\
\text { 4hs; Gp 3: área } \\
\text { da saúde (4 hs) }\end{array}$ & Não informa & $\begin{array}{l}\text { Usuários } \\
\text { reconhecem o } \\
\text { treinamento como } \\
\text { instrumento } \\
\text { importante; } \\
\text { muitos têm } \\
\text { demonstrado } \\
\text { satisfação. }\end{array}$ \\
\hline
\end{tabular}

TABELA 3

Relatos de ações informacionais fora de biblioteca na área de saúde

\begin{tabular}{|c|c|c|c|c|}
\hline & Objetivos & $\begin{array}{l}\text { População } \\
\text { estudada }\end{array}$ & Metod. & Resultados /comentários \\
\hline $\begin{array}{l}\text { Crestana, } \\
\text { M.F.; } \\
\text { Amatuzzi, } \\
\text { M. L. }\end{array}$ & $\begin{array}{l}\text { Relato de experiência } \\
\text { de dois projetos de } \\
\text { ensino-pesquisa- } \\
\text { extensão do Dep. } \\
\text { Ortopedia e } \\
\text { Traumatologia do } \\
\text { HC/FMUSP, tendo } \\
\text { em comum o uso da } \\
\text { informação: a) para } \\
\text { fins didáticos e } \\
\text { divulgação; b) } \\
\text { levando informações } \\
\text { de saúde para a } \\
\text { população na forma } \\
\text { de campanhas } \\
\text { educativas e } \\
\text { preventivas }\end{array}$ & $\begin{array}{l}\text { Membros de } \\
\text { dois grupos, } \\
\text { equipe de } \\
\text { profissionais da } \\
\text { biblioteca (não } \\
\text { informado o } \\
\text { número de } \\
\text { pessoas } \\
\text { entrevistadas) }\end{array}$ & $\begin{array}{l}\text { Estudo } \\
\text { de caso } \\
\text { Análise } \\
\text { documen- } \\
\text { tal } \\
\text { (sem } \\
\text { apresenta } \\
\text { ção de } \\
\text { dados ) }\end{array}$ & $\begin{array}{l}\text { Produção de material de } \\
\text { divulgação e didático } \\
\text { Campanhas educativas } \\
\text { (do mergulho em águas } \\
\text { rasas, da saúde na terceira } \\
\text { idade, de prevenção de } \\
\text { acidentes } \\
\text { automobilísticos, de } \\
\text { prevenção da } \\
\text { osteoporose) } \\
\text { Por ser um relato de } \\
\text { experiência, não se } \\
\text { configura nos moldes de } \\
\text { um relato científico }\end{array}$ \\
\hline $\begin{array}{l}\text { Gonçalves } \\
\text { O.S. L.; } \\
\text { Beraquet, } \\
\text { V.S. M. }\end{array}$ & $\begin{array}{l}\text { Análise dos processos } \\
\text { de tomada de decisão } \\
\text { dos gestores da saúde } \\
\text { pública vinculados à } \\
\text { SMS de Campinas/SP } \\
\text { no que diz respeito ao } \\
\text { uso de informação e } \\
\text { de conhecimento a } \\
\text { fim de avaliar e } \\
\text { propor melhorias. }\end{array}$ & $\begin{array}{l}\text { Sete gestores, } \\
\text { atuantes nos } \\
\text { distritos e na } \\
\text { Vigilância da } \\
\text { Saúde }\end{array}$ & $\begin{array}{l}\text { Entrevis- } \\
\text { tas semi- } \\
\text { estrutura } \\
\text { das }\end{array}$ & $\begin{array}{l}\text { Quando questionados } \\
\text { sobre a qualidade das } \\
\text { decisões tomadas com } \\
\text { base no uso da } \\
\text { informação e do } \\
\text { conhecimento, } 43 \% \text { (3) } \\
\text { dos entrevistados não } \\
\text { fizeram julgamento, } \\
\text { apenas comentários; } \\
57 \text { \% (4) julgaram } \\
\text { como boa a qualidade } \\
\text { das decisões. } \\
\text { Não apresenta os } \\
\text { comentários. }\end{array}$ \\
\hline
\end{tabular}




\section{REFERÊNCIAS}

ALLIEZ, E. Deleuze filosofia virtual. São Paulo: Ed. 34, 1996.

CRESTANA, M. F. A informação, o ensino médico e os cuidados de saúde na construção da cidadania: experiência do departamento de ortopedia e traumatologia do hospital das clínicas/Faculdade da Universidade de São Paulo. 2002. Disponível em: < http://www.usp.br/sibi/ boletim inter/download/cricsinformacao.pdf $>$. Acesso em: 20 set. 2005.

CUENCA, A. M. B. O usuário final da busca informatizada: avaliação da capacitação no acesso a bases de dados em biblioteca acadêmica. Ciência da Informação, v. 28, n. 3, p. 293-301, set./dez. 1999.

CURTY, M. G. Busca de informação para desenvolvimento das atividades acadêmicas pelos médicos docentes da UEM. In: CONGRESSO DE BIBLIOTECONOMIA, 12., 2003, Recife. Anais eletrônicos... Disponível em: < http://www.sibi.ufrj.br/snbu/snbu2002/ abstract/62.a.htm>. Acesso em: 23 out. 2005.

DELEUZE, G.; GUATTARI, F. Mil platôs: capitalismo e esquisofrenia. São Paulo: Ed. 34, 1995. v. 1. . Conversações. Rio de Janeiro, Ed. 34, 1992. p. 47.

. O atual e o virtual. In: ALLIEZ, E. Deleuze filosofia virtual. Rio de Janeiro: Ed. 34, 1996. p. 49-57.

FOUCAULT, M. Microfísica do poder. Rio de Janeiro, Edições Graal, 1979.

FROHMANN. The role of the scientific paper in science information systems.

Presented at The Conference on the History and Heritage of Science Information

Systems. Pittsburgh, Pennsylvania, 23-25 October 1998. Disponível em:

<http://www.fims.uwo.ca/people/faculty/frohmann/ Publications.htm >. Acesso em: 08 mar. 2004.

GALLO, S. Deleuze $\mathscr{E}$ a educação. Belo Horizonte: Autêntica, 2003.

GIRELLO, M. A utilização do serviço de treinamento e consulta às bases de dados pelos usuários da biblioteca da Faculdade de Odontologia de Piracicaba - Unicamp. In: CONGRESSO DE BIBliOTECONOMIA, 12., Recife, 2003. Anais eletrônicos... Disponível em: < http://www.sibi.ufrj.br/snbu/snbu2002/abstract/ 62.a.htm >. Acesso em: 23 out. 2005.

GONÇALVES, O. S. L.; BERAQUET, V. M. Gestão da informação e do conhecimento: um estudo exploratório com os gestores da saúde pública de Campinas/SP. In: CONGRESSO MUNDIAL DE SAÚDE E BIBLIOTECAS, 9., 2005, Salvador. Anais eletrônicos... Disponível em: http://www.icm19.org/program/track3/public/documents/ Simone\%20Lucas\%20Goncalves\%20de\%200liveira-173648.doc. Acesso em: 20 out. 2005.
LATOUR, B.; WOOLGAR, S. A vida de laboratório: a produção de fatos científicos. Rio de Janeiro: Relume Dumará, 1997.

LENOIR, Timothy. Registrando a ciência os textos científicos e as materialidades da comunicação. Episteme, Porto Alegre, v. 2, n. 4, p. 33-53, 1997.

LIMA, H. M. C. Experiências em buscas de informações por residentes de medicina. Revista Brasileira de Educação Médica, v. 29, n. 1, jan./abr. 2005.

MARQUETIS, E. M. et al. Avaliação do programa de capacitação de usuários do sistema de bibliotecas da Unicamp. In: CONGRESSO DE BIBLIOTECONOMIA, 12., 2003, Recife. Anais eletrônicos... Disponível em: < http://www.sibi.ufrj.br/snbu/snbu2002/abstract/ 45.a.htm >. Acesso em: 20 out. 2005.

MOSER, E. M. Acesso às bases de dados online: rotina de treinamento para usuários da biblioteca central da Furb. In: CONGRESSO DE BIBliOTECONOMIA, 12., 2003, Recife. Anais eletrônicos... Disponível em: < http://www.sibi.ufrj.br/snbu/snbu2002/abstract/ 62.a.htm >. Acesso em: 23 out. 2005.

MOSTAFA, S. O artigo de ciência como fato e artefato cultural. Educação Temática Digital, v. 6, n. 4, 2004. Disponível em: $<143.106 .58 .55 /$ revista/viewarticle.php?id=27>. Acesso em: 20 out. 2005.

PEIXOTO, M. A. P.: MATTOS, T. M. Fontes de estudo na escola médica - recursos instrucionais utilizados por alunos de medicina da região sudeste do Brasil. Revista Brasileira de Educação Médica, v. 24, n. 3, out./dez. 2000.

PIMENTA, S; GHEDIN, E. (Org.). Professor reflexivo no Brasil: gênese e crítica de um conceito. São Paulo: Cortez, 2002.

SACKETT D. L. et al. Medicina baseada em evidências: prática e ensino. 2. ed. Porto Alegre: Artmed, 2003.

SHERSHNEVA, M. et al. Learning to use learning resources during medical school and residency. Journal Medical Library Association, v. 93, n. 2, p. 263-270, Apr. 2005

SLOTNNICK, H; HARRIS, T. R.; ANTONENKO, D. R. Changes in learning-resource use across physicians learning spaces. Bulletin Medical Library Association, v. 89, n. 2, Apr. 2001.

THOMPSON, M. Characteristics of information resources preferred by primary care physicians. Bulletin Medical Library Association, v. 85, n. 2, p. 187-192, Apr. 1997. 